\title{
MARKERS ASSOCIATED WITH CAROTENOIDS CONTENT IN VIR BRASSICA RAPA L. COLLECTION
}

\author{
Fateev D.A., Solovyeva A.E., Kurina A.B., Artemyeva A.M. \\ FSBSI «Federal Research Center the N. I. Vavilov All-Russian Institute of Plant Genetic \\ Resources»(VIR),dmtfateev@gmail.com
}

The VIR world wide collection contains more than 51,600 accessions of vegetable and cucurbit crops from 98 countries, including 7303 accessions of vegetable brassicas received by VIR since 1923. The uniqueness of the VIR Brassicaceae family crops collections reaches 50\%. The collection includes accessions of various status: landraces, old and advanced cultivars, inbred and double haploid lines, hybrid populations.

Brassica rapa L. is a very diverse species with the longest cultivation history, and encompasses leafy and rooted vegetables, and oilseeds. The leafy vegetables include heading Chinese cabbage, pak choi, tatsoi, wutacai, mizuna, komatsuna, and neep greens; the turnips include vegetable and fodder types. In B. rapa leafy crops the highest content of carotenoids and phenolic compounds among other brassicas has been determined. Carotenes, including $\beta$ carotene, are the important components of vegetable products quality. Antioxidant $\beta$-carotene serves a precursor of vitamin A (retinol), has immune stimulating and adaptogenic effects.Association mapping in plants uses linkage disequilibrium (LD) that presents in natural and breeding populations including collections of plant genetic resources in genebank. Using this tool, the genetic diversity expressed as allelic polymorphism can be related to the observed phenotypic valuable characters. 
40 B. rapa accessions from the VIR collection encompassing a wide range of carotenoids content types different geographical origin were used in this study. The plants were grown in the field in VIR Pushkin Branch (St-Petersburg). Biochemical analysis of the content of carotenoids, carotenes and $\beta$-carotene was conducted by standard methods. For genotyping of accessions and association mapping two or-linked SSR markers BRMS-007 $(\mathrm{R} 5,102.3 \mathrm{cM})$ and BRMS-051 $(\mathrm{R} 9,58.4 \mathrm{cM})$ were applied. These markers were used for QTL analysis of B.rapa mapping populations DH30 and DH38; in our previous studies were found that they connect with content of carotenoids. For association mapping the software Tassel v. 4.0 was used.

The biochemical analysis of the genotypes revealed large variations of carotenoids content between $4.73 \%$ and $36.51 \mathrm{mg} / 100 \mathrm{~g}$ (the highest content in par choi Choo F1), carotenes from 1.29 to $16.08 \mathrm{mg} / 100 \mathrm{~g}$ (the highest content in leafy turnip Red Komatsuna), $\beta$-carotene from 0.86 to $6.68 \mathrm{mg} / 100 \mathrm{~g}$ (the highest content in Choo F1, tatsoi Misome). Association mapping using GLM and MLM models identified significant marker-trait associations $(\mathrm{p}<0.05)$ for contents of biochemical compounds. We identified 3 alleles controlling content of carotenoids, carotenes and $\beta$-carotene. Allele $270 \mathrm{bp}$ (BRMS-51) controlling carotenoids (avg. marker presence 12.76, marker absence $18.32 \mathrm{mg} / 100 \mathrm{~g} ; \mathrm{p}=$ 0.003 ), carotenes (avg. presence 3.21, absence 4,91 mg/100 g; $\mathrm{p}=0.005$ ), $\beta$-carotene (avg. presence 2.28, absence 3,39 $\mathrm{mg} / 100 \mathrm{~g} ; \mathrm{p}=0.007)$ content was observed. Allele $158 \mathrm{bp}$ (BRMS-007) controlling carotenoids (avg. marker press. 12.77, abs.18,68 mg/100 g; p = 0.013 ), carotenes (avg. press. 2.80, abs. 5,00; $\mathrm{p}=0.006$ ), $\beta$-carotene (avg. press. 2.41, abs.3,39; $\mathrm{p}=0.032$ ) content was found. Allele $135 \mathrm{bp}$ (BRMS-007) controls content of carotenoids (avg. press. 20.58, abs.12.84; $\mathrm{p}=0.017$ ), carotenes (avg. press. 5.31, abs.3.47; $\mathrm{p}=$ 0.027 ), $\beta$-carotene (avg. press. 3.69, abs. 2.42; $\mathrm{p}=0.025$ ) content.

In the present study, we performed the results of association mapping and identified SSR markers associated with carotenoids, carotenes and $\beta$-carotene content in B.rapa for screening of genetic resources collections and breeding material. Identification of loci associated with valuable traits facilitates marker-assisted selection to increase crop productivity and quality.

The reported study was partially supported by RFBR, research project No. 20-516-00017 bel_a "Study of genetic mechanisms to regulate the accumulation of anthocyanins and carotenoids in vegetable Solanaceae and Brassicaceae crops". 